\title{
PERAN BIKER TRAVELERS SEBAGAI STAKEHOLDER \\ DALAM MEMPROMOSIKAN BATUR UNESCO \\ GLOBAL GEOPARK, KINTAMANI, BALI
}

\author{
Wahyu Ning Tyas \\ Universitas Udayana \\ Email: ningtyas.wahyu@yahoo.com \\ Made Sudiana Mahendra \\ Universitas Udayana \\ Email: mahendramade@yahoo.com \\ Gde Indra Bhaskara \\ Fakultas Pariwisata Universitas Udayana \\ Email: gbhaskara@unud.ac.id
}

\begin{abstract}
This study aims to determine the role of biker travelers in promoting Batur UNESCO Global Geopark, Kintamani, and to know their potition as a stakeholder. The research method used was descriptive qualitative. The technique of determining informants using purposive sampling. Data collected through observation, interviews, and documentation. The results show that Denpasar biker travelers have some roles in promoting Batur UNESCO Global Geopark through activities on their motorbike communities such as, touring, sunmori (sunday morning ride), planting trees in tourist areas, Bali no trash challenge activities, and using features on Instagram social media (hashtag (\#), tag people, tag location and caption) to share photos and videos of their trip. Biker travelers are identified in the type of dormant stakeholder. The characteristics of this stakeholders are people or groups who have little or no interaction/involvement. It is recommended to the manager of Batur UNESCO Global Geopark to make an anual event that suits the biker travelers' preferences, make an attractive brochure about tourism spot in Batur geopark, dare to invest in promotion, and optimize the synergy among stakeholders, particularly the Denpasar biker travelers in the development of the Batur UNESCO Global Geopark tourism promotion.
\end{abstract}

Keywords: biker travelers, stakeholders, promotion 


\section{Pendahuluan}

Komunitas motor berkumpul atas kesamaan hobi otomotif dan aktivitas touring (tur/perjalanan) menggunakan sepeda motor, mereka kemudian membentuk klub motor masing-masing sesuai dengan jenis motor atau berdasarkan visi dan misi yang sama. Klub motor di Indonesia memiliki sebuah wadah yang disebut IMI (Ikatan Motor Indonesia). IMI merupakan organisasi di bawah pemerintah yang berfungsi untuk memfasilitasi industri olahraga otomotif, bekerjasama di bidang pariwisata dan sektor sosial (IMI, 2018). IMI ada di 34 Provinsi di Indonesia, termasuk IMI Bali. Keuntungan jika tergabung dalam IMI yaitu agar klub motor bersifat legal dan akses informasi terkait kegiatan otomotif pun menjadi lebih mudah didapatkan, namun banyak juga klub motor yang bersifat independent.

Biker travelers Denpasar memiliki kegiatan yang berindikasi terhadap kegiatan pariwisata, misalnya touring dengan tujuan sebuah destinasi wisata serta penggunaan media sosial yang dapat menjadi promosi secara tidak langsung. Seperti yang dikatakan oleh Eddi (biker travelers), para riders otomatis akan mengangkat tempattempat yang didatangi lewat akun media sosial mereka. Jadi riding secara tidak langsung membawa dampak positif kepada pengembangan pariwisata, khususnya di Indonesia (CNN Indonesia, 2018). Salah satu upaya kerja sama antara pemerintah dengan klub motor untuk mempromosikan daya tarik wisata dilakukan oleh Gubernur Jawa Barat, Ridwan Kamil. Dalam artikel yang berjudul "Promosikan Wisata, Ridwan Kamil Gandeng Komunitas Motor Jelajahi Jabar" tersebut dijelaskan bahwa Gubernur terpilih Jawa Barat, Ridwan Kamil berkendara bersama puluhan motor klasik dari Biker Brotherhood 1\% MC dan klub motor besar lainnya (Inews, 2018).

Salah satu destinasi wisata tujuan touring favorit para biker travelers di Denpasar adalah Batur UNESCO Global Geopark, Kintamani. Batur UNESCO Global Geopark (BUGG) merupakan destinasi wisata alam yang indah dengan berbagai jenis wisata seperti wisata alam, wisata budaya, wisata religi, wisata minat khusus dan wisata edukasi, namun wisata yang digemari oleh para bikers saat berkunjung pada BUGG 
adalah wisata alam seperti menikmati view point dibeberapa spot wisata seperti black lava dan view point dari atas dinding kaldera pada Desa Batur Selatan dengan view Gunung Batur dan Danau Batur. Ada beberapa komunitas yang aktif berwisata di kawasan BUGG seperti, komunitas sepeda, komunitas pendaki gunung, komunitas motor offroad, dan onroad, dll., namun demikian komunitas motor yang disebut biker travelers Denpasar dengan jenis motor Honda yang didesain untuk jalan on road menjadi fokus dari penelitian ini. Keberadaan komunitas motor ini dapat menjadi peluang untuk promosi wisata karena aktivitas mereka pada komunitas motor dan media sosial yang dapat menjadi media persebaran informasi yang cepat dan masal. Berdasarkan hal tersebut, paper ini fokus membahas tentang peran biker travelers Denpasar dalam mempromosikan Batur UNESCO Global Geopark, serta mengetahui posisi mereka sebagai stakeholder pada destinasi wisata Batur UNESCO Global Geopark.

\section{Landasan Teori dan Konsep}

Sykes dan Kelly (2012:6) mendefinisikan pariwisata sepeda motor (motorcycle tourism) mencakup empat elemen berikut :

1. Pariwisata melibatkan perjalanan jauh dari rumah yang tujuan utamanya adalah liburan atau rekreasi.

2. Perjalanan dapat mencakup partisipasi dalam acara olahraga atau kehadiran di acara yang diselenggarakan untuk keuntungan komersial dan amal, atau bersepeda motor yang diorganisir secara independen (diadaptasi dari definisi pariwisata sepeda Lamont (2010) di Australia).

3. Wisatawan itu bisa pasif atau aktif (penumpang sepeda motor atau pengemudi), dan perjalanan itu bisa berupa perjalanan sehari atau menginap. Berkeliling dengan sepeda motor yang dilacak dari satu tempat ke tempat lain juga memenuhi syarat. Menggunakan sepeda motor untuk transportasi harian tidak memenuhi syarat. 
4. Sepeda motor, meminjam dari definisi Morris (2010), "kendaraan bertenaga dua atau tiga roda yang dirancang untuk penggunaan di jalan, atau di jalan ganda (on dan off-road). "Sepeda motor yang ditetapkan untuk pariwisata sepeda motor mencakup tiga kategori utama sepeda motor yang digunakan untuk tur, menjelajah, dan sepeda motor sport-tour. Tetapi hanya sepeda motor off-road yang secara khusus dikecualikan dari pariwisata sepeda motor.

Motorcycle tourism (pariwisata sepeda motor) adalah sebuah konsep perjalanan menggunakan motor beroda dua atau tiga yang digunakan di jalan off-road atau on road dengan tujuan tur, menghadiri acara olahraga dan sederhananya melakukan perjalanan dan bertemu sesama biker travelers di jalanan. Pada penelitian ini, konsep pariwisata motor yang dimaksud adalah para biker travelers Honda Denpasar yang sudah pernah melakukan touring ke BUGG.

Biker adalah pengendara sepeda motor, terutama yang merupakan anggota geng atau kelompok (Oxford Dictionary, 2000). Menurut Hersh (2003 dalam Way, Roberts dan Turner, 2010) pengendara motor dewasa biasanya memiliki lebih banyak waktu dan uang untuk dihabiskan untuk kegiatan rekreasi. Morsiani (2013 dalam Scol, 2016) menyatakan, pada tahun 1950-an dan 70-an biker (pengendara sepeda motor) disorot dengan image negatif, hal ini dipengaruhi oleh film-film yang menampilkan kesan bahwa pengendara sepeda motor adalah seorang penjahat dan pemberontak, namun, pegendara sepeda motor yang dewasa telah berubah, mereka tidak hanya dewasa dari segi usia, tetapi juga waktu dan ekonomi (pendapatan), sehingga biker menjadi wisatawan yang potensial untuk penawaran produk wisata.

Motorcyclist, Motorcycle Rider, Rider atau Biker memiliki arti yang sama yaitu pengendara sepeda motor. Hanya saja di Indonesia, pengendara sepeda motor dengan minat khusus untuk melakukan perjalanan wisata dengan sepeda motor lebih populer dengan sebutan biker. Sedangkan travellers adalah seseorang yang bepergian atau sering bepergian (Oxford Dictionary, 2000). Istilah traveler dalam bahasa Inggris Amerika juga berarti wisatawan, sehingga biker travelers dapat diartikan sebagai 
seseorang yang melakukan perjalanan dengan sepeda motor atau singkatnya wisatawan motor. Bagi biker travelers, perjalanan tidak hanya tentang berpindah dari satu lokasi ke lokasi lain, tetapi juga sebuah perjalanan yang dilakukan dengan minat yang mendalam dan juga sebagai sarana pemenuhan hobi. Biker travelers yang dimaksud dalam penelitian ini adalah biker travelers Denpasar dengan kendaraan motor Honda untuk jalur on road, yang tergabung dalam sebuah klub motor di Denpasar, dan sudah pernah melakukan kegiatan touring, maupun aksi sosial pada Batur UNESCO Global Geopark, Kintamani.

Menurut Hetifah (2003 dalam Amalyah, Hamid dan Hakim, 2016), stakeholders (pemangku kepentingan) dimaknai sebagai individu, kelompok atau organisasi yang memiliki kepentingan, terlibat, atau dipengaruhi (secara positif maupun negatif) oleh kegiatan atau program pembangunan. Freeman (1984 dalam Bhaskara, 2015) mendefinisikan stakeholders sebagai kelompok atau individu yang dapat mempengaruhi atau dipengaruhi oleh pencapaian tujuan organisasi. Mitchel et al. (1997 dalam Bhaskara, 2015) mengklasifikasikan stakeholders sesuai dengan kekuatan mereka mempengaruhi legitimasi dari masing-masing korelasi stakeholders dengan organisasi dan urgensi dari stakeholders dalam organisasi.

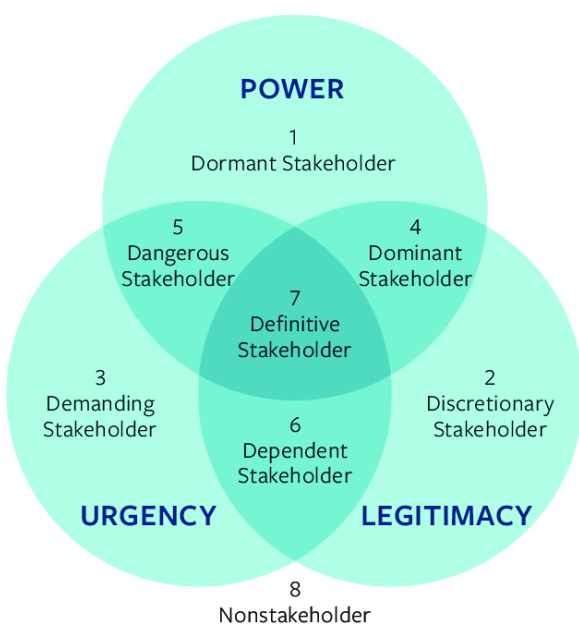

Gambar 1. Stakeholders Salience Model

Sumber: Mitchel et al. (1997 dalam Bhaskara, 2015) 
Model analisis stakeholders oleh Mitchel et al. (1997 dalam Bhaskara, 2015), menggunakan tiga atribut yang digunakan untuk menggambarkan stakeholders dan arti penting mereka dalam pengambilan keputusan dalam organisasi: power (akses ke sumber daya seperti modal dan dana), legitimacy (pernyataan yang sah menurut Undang-Undang), dan urgency (sensitivitas waktu atau sejauh mana suatu hal membutuhkan perhatian segera/secepatnya). Untuk menjelaskan lingkaran yang tumpang tindih dan untuk memfasilitasi pemahaman model pemangku kepentingan Mitchel et al. (1997), perlu untuk membongkar diagram ven dari model ini dan membangunnya kembali dalam bentuk hierarki seperti pada Tabel 1.

Tabel 1. Model Hierarki Kepentingan-Kepetingan Stakeholders

\begin{tabular}{|c|c|c|c|}
\hline Number of attributes & Attributes & $\begin{array}{c}\text { Types of } \\
\text { stakeholders }\end{array}$ & Priority \\
\hline 1 & Power & Dormant & \\
\hline 1 & Legitimacy & Discretionary & Low \\
\hline 1 & Urgency & Demanding & \\
\hline 2 & Power + Legitimacy & Dominant & \\
\hline 2 & Power + Urgency & Dangerous & Medium \\
\hline 2 & Legitimacy + Urgency & Dependent & \\
\hline 3 & $\begin{array}{l}\text { Power }+ \text { Legitimacy }+ \\
\text { Urgency }\end{array}$ & Definitive & High \\
\hline
\end{tabular}

Sumber: Mitchel et al. (1997 dalam Bhaskara, 2015)

Model stakeholders Mitchel et al. (1997 dalam Bhaskara, 2015) menggambarkan sejauh mana manajer memprioritaskan stakeholders dan menjelaskan kepada siapa dan apa yang sebenarnya harus diperhatikan oleh manajer. Jenis stakeholders dormant, discretionary dan demanding diklasifikasikan sebagai prioritas rendah (low priority) 
karena masing-masing dari mereka hanya memiliki satu atribut. Stakeholders dormant diidentifikasi oleh 'power', discretionary semata-mata hanya memiliki 'legitimacy' dan demanding hanya memiliki 'urgency'. Stakeholders yang memiliki dua atribut diklasifikasikan sebagai stakeholders prioritas menengah (medium priority). Stakeholders yang dominan memiliki dua atribut, power dan legitimacy; dangerous memiliki power dan urgency, dan dependent memiliki legitimacy dan urgency. Kepemilikan dua atribut oleh para stakeholders tersebut tercermin dalam diagram venn sebagai stakeholders definitive. Area tiga lingkaran yang tumpang tindih ini mewakili tiga atribut (power, legitimacy dan urgency) yang dimiliki oleh definitive stakeholders dan diklasifikasikan sebagai stakeholders prioritas tinggi (high priority). Berdasarkan penjelasan sebelumnya, dapat disimpulkan bahwa stakeholders merupakan aktor yang terlibat dan memiliki kepentingan dalam mengatur atau mengembangkan suatu kegiatan atau program pembangunan untuk mencapai tujuan bersama. Pada penelitian ini model yang termasuk dalam stakeholders yaitu, Akademisi, bisnis, komunitas, pemerintah, media dan tourist (wisatawan). Model stakeholders Mitchel et al. (1997 dalam Bhaskara, 2015) digunakan untuk mengetahui jenis stakeholders biker travelers Denpasar dan prioritasnya dalam promosi Batur UNSECO Global Geopark.

Hasan (2015), promosi merupakan variabel khusus pemasaran untuk menarik perhatian wisatawan potensial ke destinasi tertentu dan menikmati berbagai kegiatan yang dirancang dalam pariwisata. Sedangkan menurut Kotler dan Armstrong (2014), promosi adalah aktivitas yang mengkomunikasikan keunggulan produk dan membujuk pelanggan untuk membeli produk itu. Promosi merupakan sebuah aktivitas untuk memberitahu tentang produk suatu perusahaan, dalam penelitian ini penggunaan media sosial Instagram merupakan salah satu media promosi yang digunakan oleh biker travelers Denpasar.

\section{Metode Penelitian}


Penelitian ini merupakan penelitian kualitatif dengan mengkaji tentang peran biker travelers Denpasar sebagai stakeholder dalam mempromosikan Batur UNESCO Global Geopark. Lokasi penelitian berada di Kecamatan Kintamani, Kabupaten Bangli. Informan dalam penelitian ini adalah 15 orang biker travelers Honda yang berada di Denpasar, masyarakat di sekitar kawasan BUGG, komisi informasi dan komunikasi IMI Bali, safety riding and community supervisor PT Astra Honda Motor, Kepala Bidang Pemasaran Dinas Pariwisata dan Kebudayaan (Disparbud) Bangli, staf urusan konservasi kawasan Balai Konservasi dan Sumber Daya Alam (BKSDA) Bali, Kepala Bidang Promosi Badan Pengelola Pariwisata Batur UNESCO Global Geopark (BPPBUGG). Teknik pengumpulan data yang digunakan adalah observasi, wawancara dan studi dokumentasi. Informan ditentukan dengan menggunakan teknik purposive sampling. Analisis data yang digunakan yaitu deskriptif kualitatif.

Tahap awal yang peneliti lakukan adalah mencari informasi tentang informan dan menyiapkan daftar pertanyaan dalam pedoman wawancara, kemudian melakukan observasi dengan datang langsung ke lokasi penelitian, juga menggunakan bantuan kamera dan catatan lapangan, melakukan studi dokumentasi yaitu mengumpulkan data terkait profil BUGG, membaca artikel atau berita terkait BUGG di internet dan melihat aktivitas biker travelers pada media sosial Instagram. Reduksi data dalam penelitian ini dimulai dengan mendengarkan hasil rekaman wawancara, membaca jawaban informan pada pedoman wawancara, melihat hasil catatan lapangan pada saat observasi, kemudian mulai memilih dan merangkum halhal yang penting terkait peran bikers dalam promosi wisata BUGG. Penyajian data dalam penelitian ini menggunakan bentuk teks naratif dan tabel. Penegasan kesimpulan merupakan tahap terakhir dari analisis data. Peneliti menghubungkan aktivitas biker travelers pada komunitas motor dengan peran mereka pada promosi wisata BUGG maupun perannya secara umum yang berimplikasi pada kegiatan promosi wisata. Hasil analisis tersebut kemudian ditulis dalam bentuk teks naratif atau kata-kata. 


\section{Pembahasan}

Mitchel et al. (1997 dalam Bhaskara, 2015) dalam model stakeholders, mengidentifikasi 7 jenis grup stakeholders yaitu, discretionary, dependent, demanding, dormant, dangerous, dominant, dan definitive. Biker travelers Denpasar diidentifikasi dalam jenis dormant stakeholders. Jenis dormant stakeholders memiliki 1 atribut yaitu power tetapi tidak memiliki legitimacy dan urgency. Power (akses ke sumber daya seperti modal dan dana), legitimacy (pernyataan yang sah menurut Undang-Undang), dan urgency (sensitivitas waktu atau sejauh mana suatu hal membutuhkan perhatian segera/secepatnya), jenis stakeholders bersifat dinamis (dapat berubah) sesuai dengan atribut yang dimilikinnya, Mitchel et al. (1997 dalam Bhaskara, 2015). Biker travelers Denpasar didentifikasi dalam jenis stakeholders dormant karena memiliki buying power pada kawasan BUGG, hal ini terlihat dari hasil wawancara pada masyarakat di kawasan BUGG.

"Bikers sering mampir makan ke sini, biasanya satu klub motor itu ada 20-30 orang yang datang, apalagi dihari libur seperti sabtu dan minggu biasanya lebih rame bikers yang datang, dan pendapatan sehari bisa sekitar 3-4 juta. Sangat bagus sekali dengan adanya bikers ini, harapannya bawa teman yang banyak lagi ke Batur."

(Putu Eni Liyanasari, pemilik warung makan Jowet, Desa Batur Selatan)

Pernyataan dari beberapa masyarakat lain yang memiliki usaha warung makan dan restoranpun menunjukkan hal yang sama dengan yang dikatakan Putu Eni Liyanasari. Selain buying power, kuantitas jumlah anggota klub motor yang terdaftar pada IMI Bali ada 30 klub motor dengan rata-rata jumlah anggota sekitar 15 orang. Sementara klub motor yang tergabung dalam paguyuban motor honda berjumlah 13 klub motor dengan jumlah anggota sekitar belasan (13 orang) orang, kemudian klub motor yang independent dan tidak tergabung dalam IMI juga cukup banyak jumlahnya di Denpasar. Saat ini mereka juga menggunakan media sosial Instagram untuk menyimpan catatan perjalanannya. Unggahan foto dan video mereka di Instagrampun 
menjadi konsumsi pengguna internet (netizen), hal ini memungkinkan terjadinya persebaran informasi secara tidak langsung, sehingga apapun yang mereka share dapat dilihat oleh followers (pengikutnya). Biker travelers Denpasar juga memiliki beberapa kegiatan yaitu, touring, sunmori (Sunday morning ride), penanaman pohon di area wisata juga kegiatan yang bekerjasama dengan PT Astra Honda Motor yaitu, Bali no trash challenge (kegiatan membersihkan lokasi wisata dengan para bikers Honda). Promosi wisata secara tidak langsung juga dilakukan oleh para biker travelers Denpasar melalui words of mouth kepada sesama teman bikersnya, selain itu pemanfaatan fitur-fitur di Instagram seperti hashtag (\#), tag location, tag people dan caption juga dilakukan oleh para biker travelers. Berikut contoh penggunaan fitur-fitur Instagram pada akun media sosial biker travelers Denpasar.

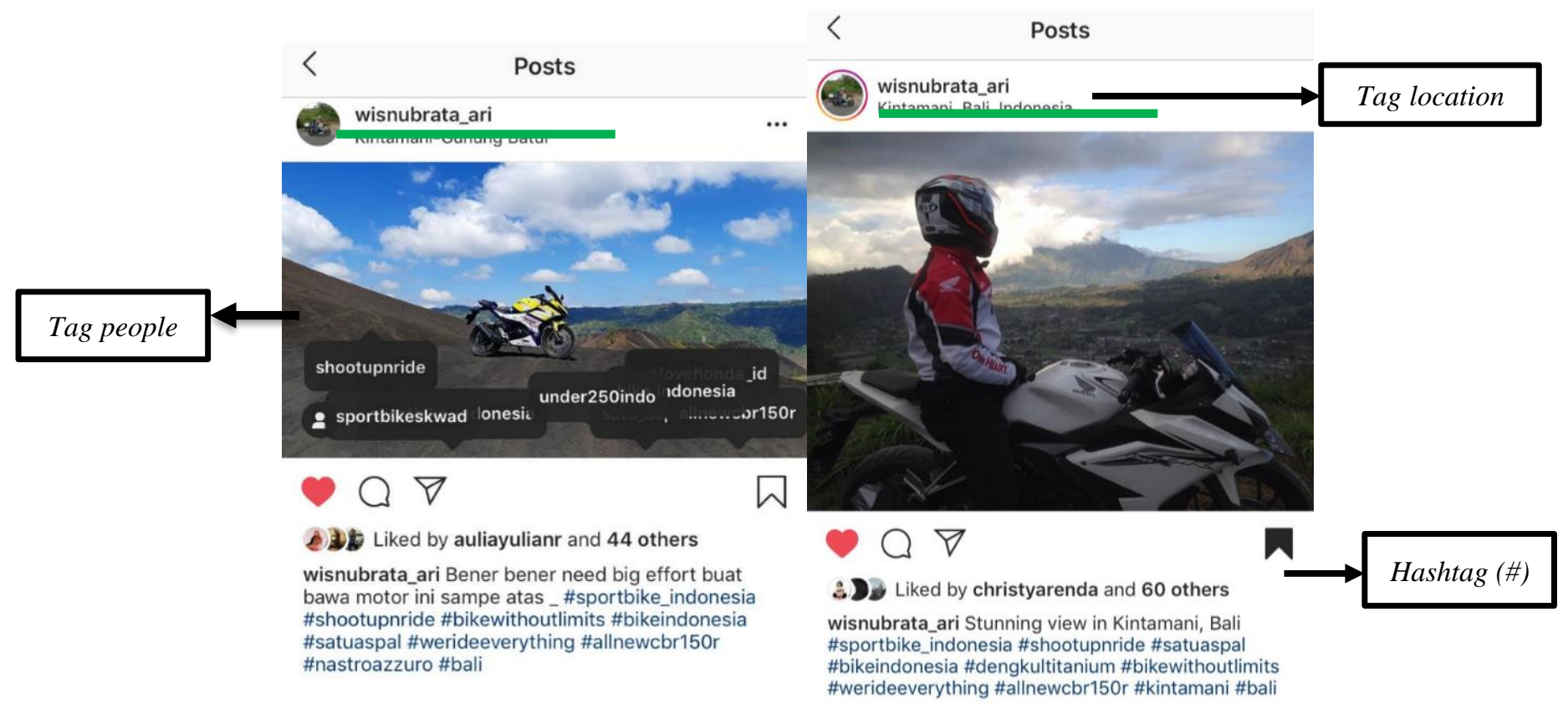

Gambar 2. Penggunaan fitur-fitur Instagram pada akun media sosial biker travelers (Sumber: Instagram wisnubrata_ari, 2019) 


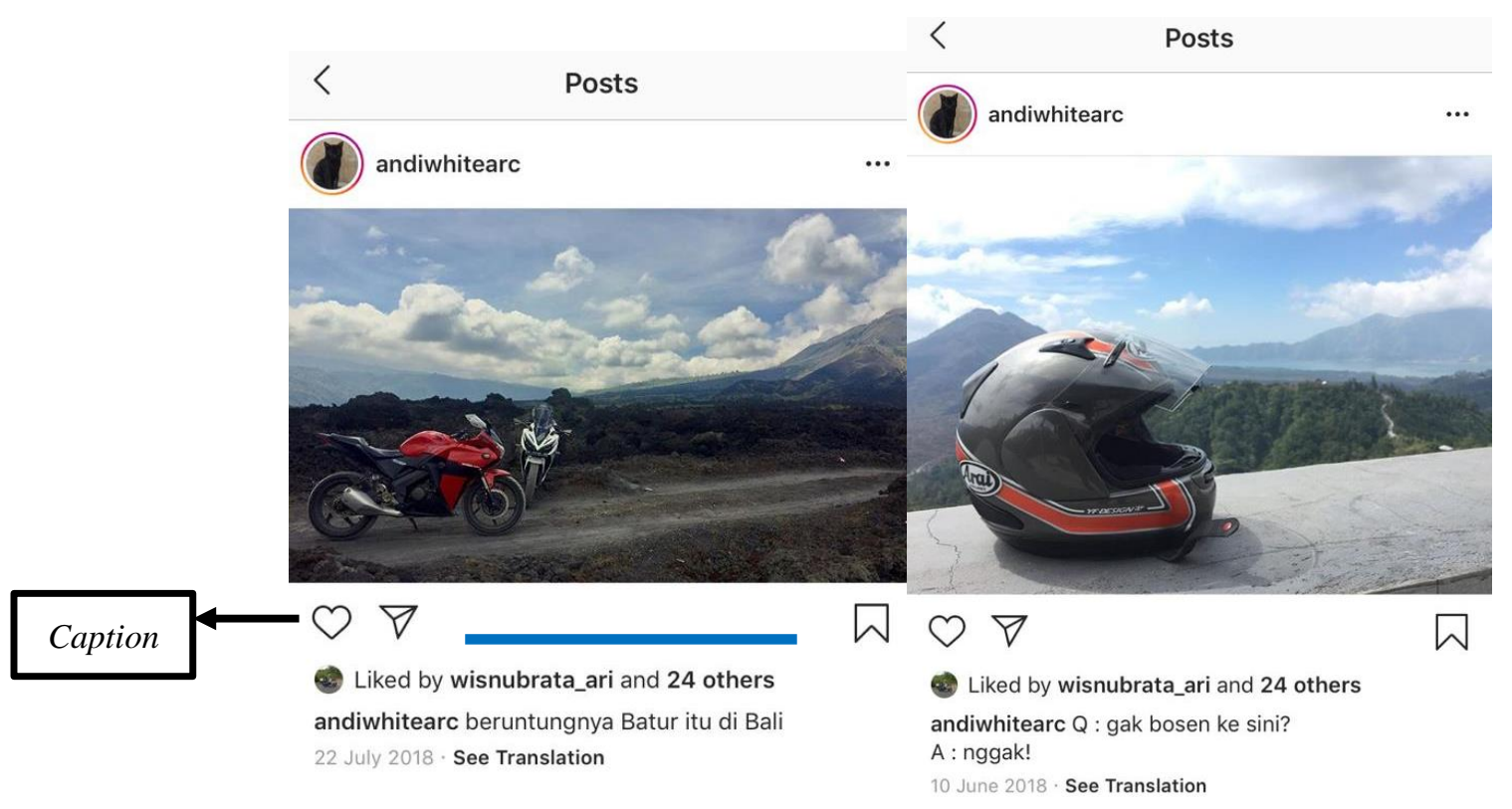

Gambar 3. penggunaan fitur-fitur Instagram pada akun media sosial biker travelers (Sumber: Instagram andiwhitearc, 2019)

Penggunaan fitur-fitur Instagram yang dilakukan oleh biker travelers Denpasar secara tidak langsung dapat memudahkan pencarian tentang BUGG pada media sosial Instagram, namun pada penggunaan hashtag (\#) dan tag people hampir belum ada biker travelers yang menggunakan hashtag \#baturgeopark tetapi merujuk pada akunakun otomotif besar seperti, rideforpride, satuaspal, shootupnride, atau akun otomotif yang sesuai dengan klub motor mereka seperti sportbike, dll. Berdasarkan penelitian yang dilakukan oleh Cater (2017), touring sepeda motor telah tumbuh secara signifikan dalam beberapa tahun terakhir, dengan pergeseran ke arah yang lebih besar, kapasitas pengguna sepeda motor dan peningkatan usia rata-rata pengendara sepeda motor. Demografi grup ini menunjukkan bahwa, sepeda motor lebih banyak digunakan untuk tujuan rekreasi daripada bepergian. Lokasi dengan proporsi yang tinggi yaitu mengunjungi, gunung dan jalan-jalan indah lebih disukai oleh pengendara sepeda motor. Penelitian sebelumnya sejalan dengan hasil penelitian ini, bahwa bikers travelers utamanya menyukai destinasi wisata gunung dan pantai, dan juga BUGG yang berada pada ketinggian dengan pemandangan dan akses jalan yang baik serta medan yang menantang bagi para bikers. 
Berdasarkan hasil wawancara dengan 15 orang bikers travelers, dapat diketahui beberapa tempat di kawasan BUGG yang menjadi titik berhenti (stop point) favorit para bikers, berikut adalah skenario perjalanan para biker travelers di kawasan BUGG:

1. Turun melalui jalur Penelokan-Kedisan menuju Danau Batur, makan di warung makan Telaga Biru atau Resto Apung, Desa Kedisan, dengan view Danau Batur.

2. Melanjutkan perjalanan menuju geosite lava bantal, di sini batu-batuan dari muntahan Gunung Batur ditutupi oleh tumbuhan yang berwarna kuning, sehingga terlihat seperti padang savana dengan background Gunung Batur, di geosite lava bantal ini, kemudian bikers mengambil foto.

3. Melanjutkan perjalanan mengelilingi Gunung Batur melalui Desa Songan A dan Desa Songan B, kemudian berhenti di geosite 19 dan 20, kemudian mengambil foto. Di geosite 19 dan 20 ini terdapat bongkahan batu-batu besar berwarna hitam dan terlihat longsoran pasir yang juga berwarna hitam dari puncak Gunung Batur. Di geosite 19 dan 20 ini terdapat beberapa gazebo untuk beristirahat dan papan informasi terkait sejarah terbentuknya belantara lava 1968 dan komposisi yang dikandungnya.

4. Melanjutkan perjalanan ke black lava, dari black lava jalur off-road bikers bisa langsung keluar melalui Jl.Culali. Black lava ini terletak di Pos 3 yang dikelola oleh BKSDA, spot wisata ini biasanya digunakan oleh para wisatawan dengan motor trail, karena medan yang dilalui adalah batuan tajam dan bentangan bukit pasir berwarna hitam, sehingga, karakter motor on-road sulit untuk melalui jalan ini. Di spot black lava ini terdapat bongkahan batu-batu besar berwarna hitam dengan background Gunung Batur dan beberapa gazebo untuk beristirahat.

5. Keluar melalui jalan di pertigaan penelokan, dan makan siang di Warung Jowet, Desa Batur Selatan dengan view Gunung Batur dan Danau Batur dari ketinggian. 
6. Spot foto lainnya yang biasa dikunjungi oleh bikers terletak di Desa Pinggan dan Desa Sukawana, kedua desa tersebut berada di atas dinding kaldera geopark, sehingga view point dari sana sangat indah untuk menikmati pemandangan desa di bawah kaldera, pemandangan Gunung Batur dan matahari terbit.

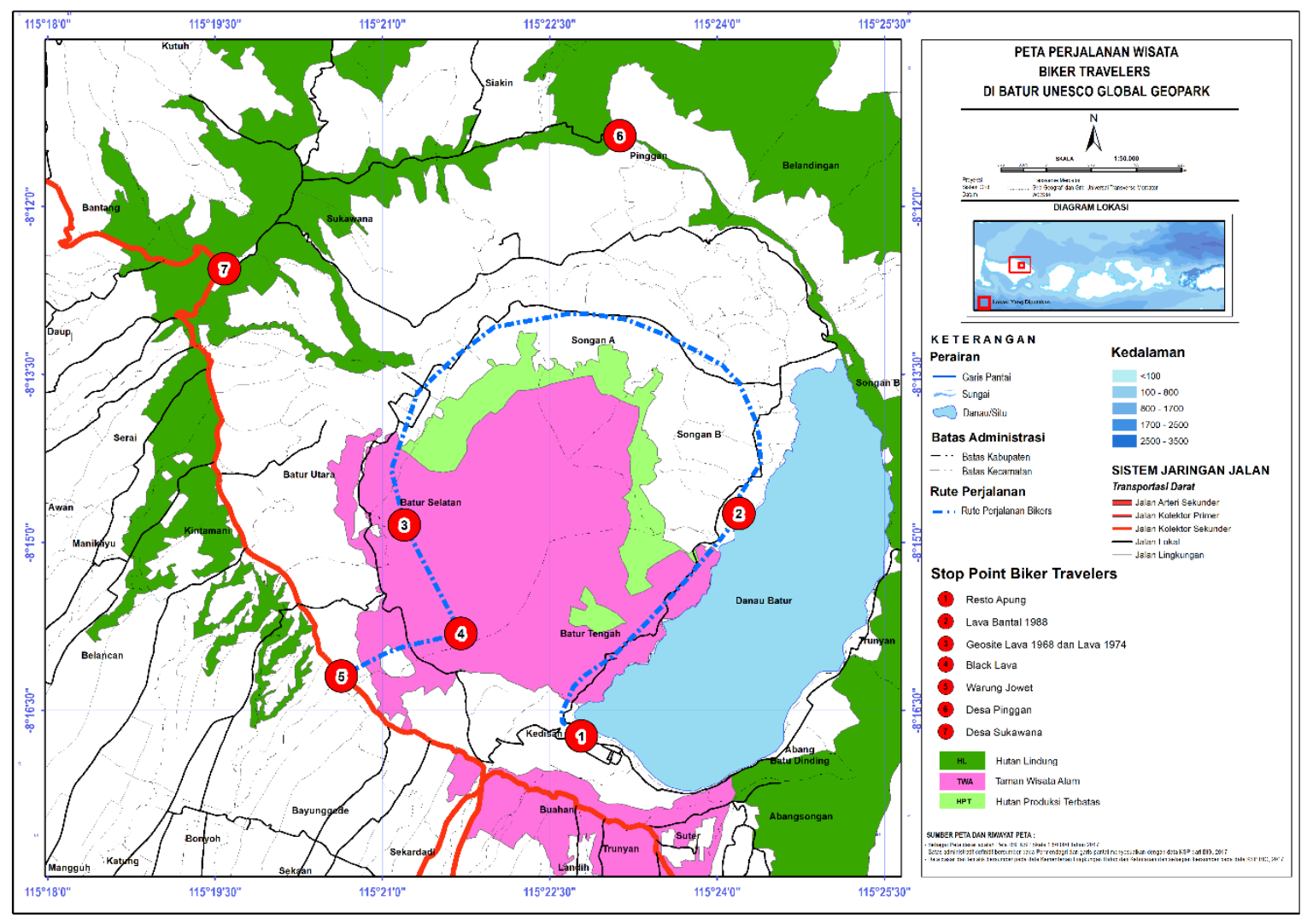

Gambar 4. Peta perjalanan wisata biker travelers di Batur UNESCO Global Geopark

\section{Simpulan dan Saran}

Biker travelers Denpasar memiliki peran sebagai sebagai stakeholder dalam mempromosikan Batur UNESCO global geopark melalui kegiatan pada komunitas motor mereka seperti, touring, sunmori (sunday morning ride), penanaman pohon di area wisata juga kegiatan yang bekerjasama dengan PT Astra Honda Motor yaitu, Bali no trash challenge, serta penggunaan fitur-fitur pada media sosial Instagram yang mereka gunakan untuk membagikan foto dan video perjalanan mereka. Biker travelers 
Denpasar diidentifikasi dalam jenis dormant stakeholders. Karakter dormant stakeholders adalah orang atau kelompok yang sedikit atau tidak memiliki interaksi/keterlibatan.

Saran untuk untuk pengelola Batur UNESCO Global Geopark, Kintamani dalam hal ini BPPBUGG (Badan Pengelola Pariwisata Batur UNESCO Global Geopark, BKSDA (Balai Konservasi Sumber Daya Alam) Bali, dan Disparbud (Dinas Pariwisata dan Kebudayaan) Bangli, sebaiknya membuat acara tahunan yang sesuai dengan preferensi bikers juga masih memenuhi standar aturan geopark, membuat brosur potensi wisata Batur UNESCO global geopark yang atraktif dan diberikan pada saat wisatawan membayar biaya retribusi, mengundang selebgram, Youtuber, Blogger, dan influencer yang memiliki banyak followers, serta berani berinvestasi dalam promosi wisata sembari terus membenahi poin-poin dalam komponen pariwisata (Attraction, Amenity, Accecibility dan Anchilary).

\section{Ucapan Terima Kasih}

Penulis menyampaikan ucapan terima kasih kepada Prof. Made Sudiana Mahendra, MappSc.,Ph.D.,C.EIA., selaku pembimbing I yang telah memberikan arahan dan dengan penuh kesabaran membimbing peneliti dalam menyelesaikan tulisan ini. Terima kasih kepada Gde Indra Bhaskara, MSc.,Ph.D., selaku pembimbing II yang telah memberikan masukan dan saran untuk penyempurnaan tulisan ini. Selanjutnya penulis mengucapkan terima kasih kepada semua pihak yang telah menyediakan waktu untuk berdiskusi dan membantu dalam menyelesaikan tulisan ini.

\section{Daftar Pustaka}

Amalyah, R., Hamid, D., dan Hakim, L. 2016. Peran Stakeholder Pariwisata Dalam Pengembangan Pulau Samalona Sebagai Destinasi Wisata Bahari. Jurnal Administrasi Bisnis, 37(1), pp.158-163. 
Bhaskara, G.I. 2015. “The Local Community As a Stakeholder Group and It's Participation in UNESCO's World Heritage Nomination Process: Jatiluwih Village, Bali, Indonesia" (Dissertation). England: Bornemouth University.

Cater, Carl I. 2017. Tourism on two wheels: Patterns of motorcycle leisure in Wales. Tourism Management, 2017, 61: 180-189.

Hasan, A. 2015. Tourism Marketing. Yogyakarta: Center for Academic Publishing Service.

Ikatan Motor Indonesia (IMI). 2019. Tentang IMI.[cited 2019 November, 21]. Available from: URL: http://imi.co.id/imi/organisasi

Kotler, P. dan Armstrong, G. 2014. Principle Of Marketing. 15 ${ }^{\text {th }}$ Edition. New Jearsey: Pearson Prentice Hall.

Oxford Advanced Learner's Dictionary. 2000. Oxford University. $6^{\text {th }}$ edition.

Pasha, Y. 2018. Promosikan Wisata, Ridwan Kamil Gandeng Komunitas Motor Jelajahi Jabar.[cited 2018 Oct. 13]. Available from: URL: https://www.inews.id/daerah/jabar/196869/promosikan-wisata-ridwan-kamilgandeng-komunitas-motor-jelajahi-jabar

Rahmadsyah, A. 2018. Mengangkangi Motor Sambil Mempromosikan Wisata.[cited Jun. 2018]. Available from: URL: https://www.cnnindonesia.com/gayahidup/20180304213806-269-280391/mengangkangi-motor-sambilmempromosikan-wisatam

Sykes, D.M., Kelly, K.G. dan Ireland, B.N. 2012. Mapping the Study of Motorcycle Tourism: Impacts and Opportunities. In Proceedings of International Conference on Tourism and Events: Opportunities, Impacts and Change (pp. 20-22).

\section{Profil Penulis}

Wahyu Ning Tyas lahir di Palu, pada 13 Oktober 1994. Pendidikan S1 dengan jurusan Hospitality diselesaikan di Sekolah Tinggi Pariwisata AMPTA, Yogyakarta pada 2012-2016. Kemudian melanjutkan pendidikan ke jenjang S2 jurusan Kajian Pariwisata di Universitas Udayana pada 2017-2019. 
Made Sudiana Mahendra adalah Guru Besar di Program Studi Doktor Lingkungan, Program Pascasarjanan Universitas Udayana. Ia menyelesaikan pendidikan S1 di Jurusan Teknologi Pertanian, Fakultas Pertanian Universitas Udayana pada tahun 1981, kemudian melanjutkan pendidikan pada jenjang S2 pada tahun 1986 dan jenjang S3 pada tahun 1991 di Department of Food Science and Technology, The University of New South Wales, Sydney, Australia.

Gde Indra Bhaskara MSc., Ph.D adalah dosen tetap Universitas Udayana kelahiran 19 Desember 1978. Beliau menamatkan sekolahnya di STP Nusa dua Bali pada tahun 2001 dan untuk kemudian melanjutkan program Master ke Bournemouth University pada tahun 2002-2004. Sekembalinya dari Inggris, beliau bekerja pada HES Global, sebuah perusahaan yang memfokuskan dalam mencari dan menempatkan eksekutif/pemimpin-pemimpin perusahaan di seluruh dunia pada industri Perhotelan dan jasa, pada kurun waktu 2004-2006. Pada periode berikutnya, beliau mengajar di Manajemen Perhotelan Indonesia yang dikenal dengan nama MAPINDO. Menghabiskan waktu dua tahun disana, pada tahun 2008 diterima di Universitas Udayana sebagai dosen tetap. Hanya berkesempatan mengajar selama dua semester setelah diangkat menjadi dosen tetap di Universitas Udayana, beliau mendapatkan beasiswa untuk melanjutkan pendidikan S3 ke Bournemouth University di tahun 2010. 